\title{
Magnesium Cobaltate Nanowires@magnanese Dioxide Nanoflakes Core-Shell Arrays on Graphene-Decorated Nickel Foam for High-Performance Supercapacitors
}

\author{
Xiangfeng Guan ${ }^{1}$, Peihui Luo ${ }^{2}$, Xiaoyan Li $^{l}$, Yunlong Yu ${ }^{l}$, Yongjing Wang ${ }^{2, *}$ Lin Zhuo $^{l}$, Dagui Chen ${ }^{1, *}$ \\ ${ }^{1}$ College of Electronics and Information Science \& Organic Optoelectronics Engineering Research \\ Center of Fujian's Universities, Fujian Jiangxia University, Fuzhou, Fujian 350108, P.R. China \\ ${ }^{2}$ College of Environment and Resources, Fuzhou University, Fuzhou 350108, P.R. China \\ *E-mail: yjwang03@fzu.edu.cn, dgchen@fjjxu.edu.cn
}

doi: $10.20964 / 2018.05 .14$

Received: 1 January 2018 / Accepted: 17 February 2018 / Published: 10 April 2018

In this work, $\mathrm{MgCo}_{2} \mathrm{O}_{4}$ nanowires $@ \mathrm{MnO}_{2}$ nanoflakes core-shell arrays structure on graphenedecorated nickel foam were successfully prepared, which were featured by porous $\mathrm{MnO}_{2}$ nanoflakes shell and one-dimensional $\mathrm{MgCo}_{2} \mathrm{O}_{4}$ nanowires core directly grown on the graphene. The morphologies of $\mathrm{MgCo}_{2} \mathrm{O}_{4}$ nanowires @ $\mathrm{MnO}_{2}$ nanoflakes core-shell arrays can be tuned by changing the hydrothermal reaction times. Due to the synergistic effect of graphene, $\mathrm{MgCo}_{2} \mathrm{O}_{4}$ nanowires, and $\mathrm{MnO}_{2}$ nanoflakes, the optimized $\mathrm{MgCo}_{2} \mathrm{O}_{4}$ nanowires $@ \mathrm{MnO}_{2}$ nanoflakes core-shell arrays electrode materials exhibited excellent electrochemical performance such as high specific capacitances of 887.3 $\mathrm{F} \mathrm{g}^{-1}$ at a current density of $1 \mathrm{~A} \mathrm{~g}^{-1}$ and good long-term cycling stability over 3000 cycles at a high current density of $10 \mathrm{~A} \mathrm{~g}^{-1}$. The findings reported here clearly demonstrated that the core-shell arrays structure may be a promising candidate of high-performance electrode materials for supercapacitor.

Keywords: $\mathrm{MgCo}_{2} \mathrm{O}_{4} ; \mathrm{MnO}_{2}$; Core-shell arrays; Graphene; Supercapacitors

\section{$\underline{\text { FULL TEXT }}$}

(C) 2018 The Authors. Published by ESG (www.electrochemsci.org). This article is an open access article distributed under the terms and conditions of the Creative Commons Attribution license (http://creativecommons.org/licenses/by/4.0/). 